\title{
Modular three-phase ac-dc LED driver based on summing the light output of each phase
}

\author{
Ignacio Castro, Manuel Arias, Diego G. Lamar, Marta M. Hernando and Javier Sebastian \\ Departamento de Ingeniería Eléctrica, Electrónica, de Computadores y Sistemas \\ University of Oviedo \\ Gijón 33204, Spain \\ e-mail: castroignacio@uniovi.es
}

\begin{abstract}
This work proposes the driving of high power Light-Emitting Diodes (LEDs) luminaires in three phase power grids using each phase to drive an independent LED load. The driving is done by means of a boost converter in charge of controlling the current across its LED load. Moreover, each boost converter needs to achieve Power Factor Correction (PFC) to comply with IEC 61000-3-2 Class $C$ requirements. Hence, achieving unity Power Factor (PF) and low Total Harmonic Distortion (THD). Taking advantage of the light properties, the output of the LED driver will be the sum of the light of each of the phases. Therefore, a theoretical study will be carried out to observe the feasibility of removing the electrolytic capacitor while guaranteeing a flicker free behaviour of the LED luminaire, even if the current of each string is pulsating at twice the mains frequency. In order to validate the study, a prototype has been built comprised of three PFC boost converters disposing of their electrolytic capacitors. The designed prototype operates in the full range of the European three-phase line voltage, which varies between $380 \mathrm{~V}$ and $420 \mathrm{~V}$, and it supplies an output light of 42.000 Im at a maximum power of $300 \mathrm{~W}$ while achieving an electrical efficiency of $97.5 \%$.
\end{abstract}

Keywords-Ac-dc power conversion, Power factor correction, Three-phase power, LED driver, capacitor-less.

\section{INT RODUCTION}

Light-Emitting Diodes (LEDs) are becoming increasingly ubiquitous across all as pects of illumination products due to their reliability, long lifetime, energy efficiency and low maintenance requirements. These advantages make LEDs suitable to replace traditional lamps in household, commercial and industrial installations [1]. Specifically, this work focuses in replacing high power lamps, i.e. $200 \mathrm{~W}$ to $10 \mathrm{~kW}$, at almost inaccessible locations, such as tunnel lights, stadium spotlights or floodlights, where access to the three-phase power grid is also available.

Conventionally, single-phase LED drivers need to comply with both ENERGY $\operatorname{STAR}^{\circledR}[2]$, [3] and the harmonic injection regulation IEC 61000-3-2 [4]. The first, requires the driver to achieve an 0.9 Power Factor (PF) and a lifetime of more than $50,000 \mathrm{~h}$ in commercial environments. In fact, the lifetime is considered as the elapsed operating time over which the LED light source will maintain a $70 \%$ of its initial light output. The second requires the driver to comply with Class $\mathrm{C}$ for lamps of more than $25 \mathrm{~W}$. In fact, for three-phase LED drivers the regulation is not clearsince the driver falls into Class A category according to it being balanced three-phase equipment, or into Class $\mathrm{C}$ because it is also lighting equipment. It is then the aim of this work to comply with the most restrictive regulation, which is Class C. In that case, each phase of the driver will be

This work was supported in part by the Spanish Government under Project MINECO-17-DPI2016-75760-R, in part by the Principality of Asturias under Severo Ochoa grant BP14-140, Project FC-15-GRUPIN14-143 and Project SVPA-17-RIS3-4, and in part by European Regional Development Fund (ERDF) grants.

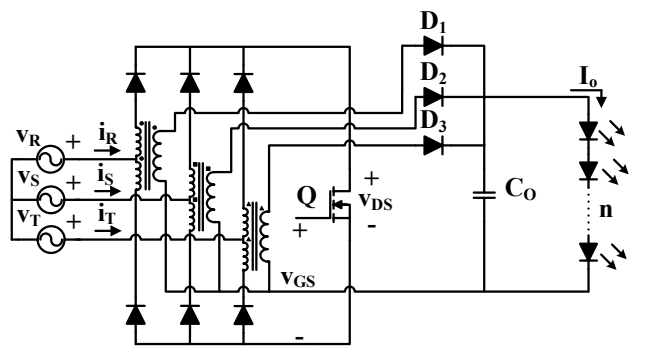

(a)

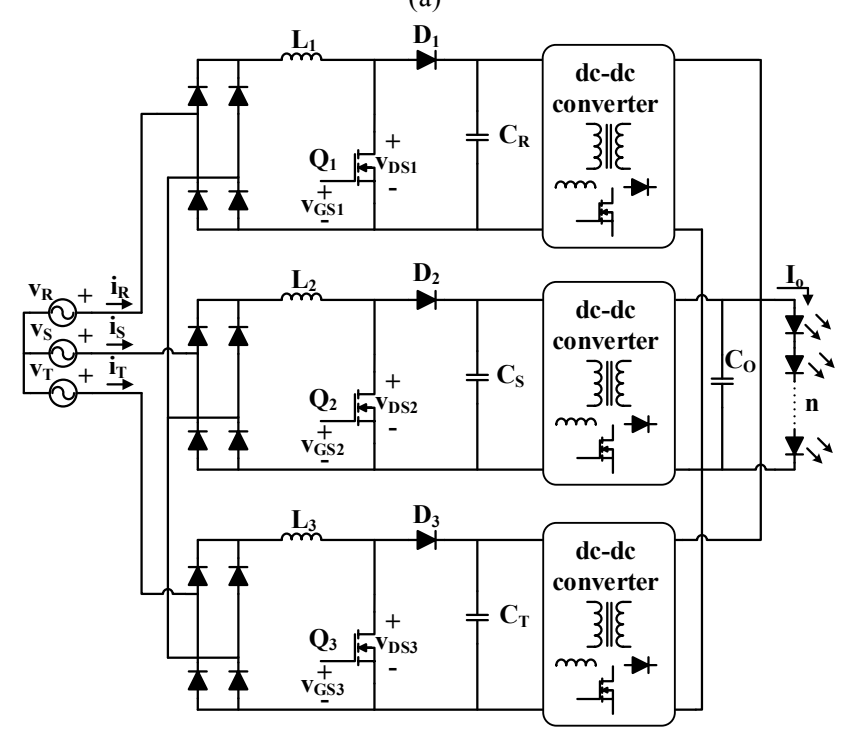

(b)

Fig. 1. Isolated three-phase rectifier. (a) Single-switch three-phase ac-dc flyback LED driver. (b) Multicell three-phase ac-dc LED driver based on using three single phase converters with fictional neutral connection.

required to demand a sinusoidalcurrent in phase with its phase voltage.

Considering that an LED driver needs to be cheap and reliable, a three-phase single-switch driver will be ideal. Indeed, a single-switch three-phase flyback converter [5], [6] has been previously proposed to drive LEDs, see Fig. 1 (a). However, its PF its roughly 0.9 for the higher voltages of the European threephase grid, its efficiency is well below the desired 90\% for an LED driver and the switch needs to withstand high voltages unless a snubber is used [7]. These characteristic make this driver unfitting for luminaries of more than $200 \mathrm{~W}$.

In accordance to previous literature, another feasible LED driver for this application, which is able to comply with the aforementioned regulation, is based on a modular approach, 
either with three cells [8], [9], or six cells to achieve higher efficiencies [9]-[11]. The proposal of these works to drive LED luminaires is to use a cell based on either a single-stage or a twostage approach per phase, see Fig. 1 (b), the latter being used for higher power luminaires due to the limitations of single-stage is olated solutions. Each cell is comprised of a boost converter, able to achieve Power Factor Correction (PFC) followed by a fixed-gain isolated step-down dc-dc converter to adequate voltages and currents to that of the LED string [12]. Similarly to the two-stage single-phase ac-dc solution, the second stage could be implemented by means of an LLC [13], an Asymmetrical Half-Bridge (AHB) [14] or a Zeta AHB [15].

The galvanic isolation of the second stage is required in this driver to connect the outputs of each cell in parallel to the LEDs, as shown in Fig. 1 (b). The parallel connection is necessary to eliminate the electrolytic capacitor, otherwise present in single-stage ac-dc converters, without controlling the second stage for that matter. However, this solution requires an excessive amount of components, which would hinder its reliability. Considering the aim of this work for low maintenance lamps placed in relatively inaccessible locations, galvanic is olation can be disposed of, as only authorized personnel should have access to the luminaire.

Some authors have tackled the design of three-phase non-isolated LED drivers based on switched capacitors [16]. These drivers can achieve high power density, high efficiency and do not require current sensing to maintain a stable light output. In contrast, the proposal requires variable frequency operation, cannot achieve full dimming condition and requires six active switches, which similarly to the multi-cell approach previously described will hinder the reliability of the driver.

In order to solve the reliability and cost issues, the proposal of this work is based on eliminating the is olated dc-dc converter that comprises the multi-cell approach, depicted in Fig. 1 (b). Hence, directly connecting an LED string to each PFC, as shown in Fig. 2. It should be noted that, this driving approach is based on using High Voltage (HV) LEDs, considering the LEDs are connected to a HV bus. The HV LED driving approach has been studied by a handful of authors thanks to the newer LEDs recently introduced in the market, showing promising results to reduce cost and increase the reliability of drivers [17].

The main benefit that all the previous three-phase LED drivers share is the disposal of the most limiting component in terms of lifetime, which is the electrolytic capacitor. This is achieved due to the non-pulsating power at the load in a balanced three-phase power grid. In the proposed driver the size of the output capacitor of each cell (i.e. $\mathrm{C}_{\mathrm{R}}, \mathrm{C}_{\mathrm{S}}$ and $\mathrm{C}_{\mathrm{T}}$, referred as $\mathrm{C}_{\mathrm{X}}$ ) cannot be diminished, if a constant current is to be assured to drive each string. In order to comply with the lifetime requirements of ENERGY $\operatorname{STAR}^{\circledR}$, this work analyzes the reduction of $C_{X}$, allowing a certain ripple to appear in terms of the current across the LEDs. This ripple will modulate the amplitude of the light due to the well-known relationship between current and light on an LED [18], hence, causing a perceptible flicker on each phase. It should be noted that, this current modulation of a low frequency ac signal plus a de signal does not have any impact in terms of the lifetime of the LEDs [19]. In contrast, the perceptible flicker both annoying and hazardous for human beings is not an issue for this solution,

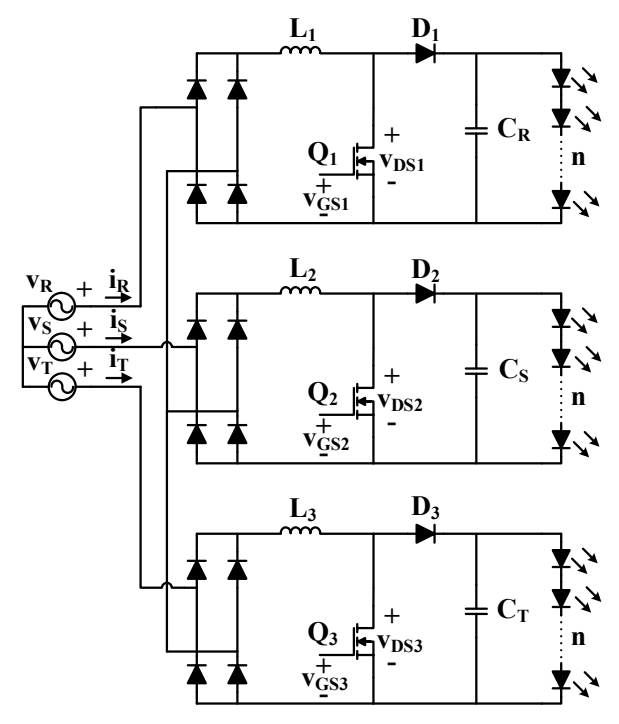

Fig. 2. Proposed LED driver based on a modular approach without galvanic isolation.

considering that the low frequency modulation of the light is cancelled between phases, rendering a constant light output [20].

Therefore, the aim of this work is studying the feasibility of removing the electrolytic capacitor in the proposed solution by means of an analytical study which is carried out in Section II. Section III focuses on the experimental results obtained with three PFC boosts working as cells, each handling a maximum power of $100 \mathrm{~W}$. This results lead to the discussion of the conclusions extracted from this work in Section IV.

\section{WORKINGPRINCIPLE}

The proposed driver takes advantage of the sum of the light output of each cell to guarantee a flicker free behaviour while disposing of the second stage required in a multi-cell three-phase LED driver. Understanding the operation of the boost converter as a Loss Free Resistor (LFR) is key to guarantee compliance with the harmonic regulation, disposal of the electrolytic capacitor and the ability to achieve full dimming. A boost converter is able to perform as an LFR by means of control, either working in CCM with a Multiplier Based Control (MBC) [21] or in Boundary Conduction Mode (BCM) [22]. This operation guarantees a resistor behaviour at its input by shaping the input current in accordance to its input voltage, and whose value, RLFR, depends on a control variable. The output performance is that of an ideal power source that depends on the demanded input power. In fact, by considering the boost as an LFR, Fig. 2 can be redrawn as Fig. 3, where the LEDs are replaced by their equivalent circuit comprised of: an ideal diode, an equivalent dynamic resistance (rLED) and an ideal voltage source, representing the knee voltage of the diode ( $V_{\gamma_{-}}$LED). The circuital problem is then reduced to a star network of equal resistors (i.e. $R_{L F R R}=R_{L F R S}=R_{L F R T}$ ) at the input, and an ideal power source feeding both the output capacitor and a string of LEDs at the output of each cell.

The first study carried out is to es timate the theoretical ripple of the low frequency component that modulates the output luminance of the driver $\left(\mathrm{L}_{0}\right)$ without an output capacitor. Then, the study will be completed using an output capacitor. 


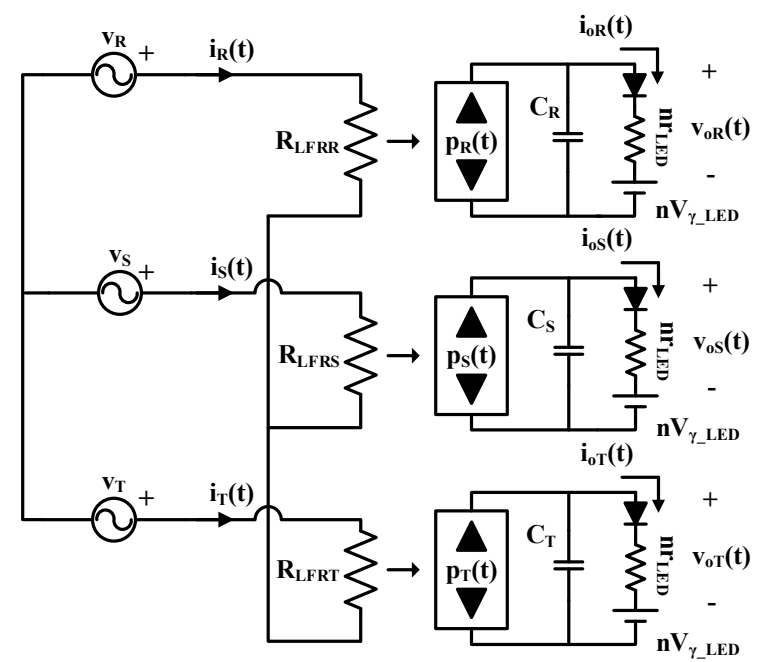

Fig. 3. Proposed HB-LED driver based on a modular approach without galvanic isolation.

In order to calculate $\mathrm{L}_{0}(\mathrm{t})$, the currents through the LEDs, $\mathrm{i}_{\mathrm{oR}}(\mathrm{t}), \mathrm{i}_{\mathrm{O}} \mathrm{S}(\mathrm{t})$ and $\mathrm{i}_{\mathrm{o}} \mathrm{T}(\mathrm{t})$, needs to be determined. Considering the sum of these currents to be proportional to the light supplied by the LEDs. Hence,

$$
\mathrm{L}_{\mathrm{o}}(\mathrm{t})=\alpha\left(\mathrm{i}_{\mathrm{oR}}(\mathrm{t})+\mathrm{i}_{\mathrm{oS}}(\mathrm{t})+\mathrm{i}_{\mathrm{oT}}(\mathrm{t})\right)
$$

where $\alpha$ represents the proportionality between the low frequency modulation of the light and the current through the LEDs.

\section{A. Withoutoutput capacitor}

This first study will shed some light on whether it is feasible to achieve a non-flicker performance when driving the LEDs with pulsating currents. The current through the LEDs can be obtained by analyzing and solving a simple circuit of a power source in parallel with the LEDs. Hence,

$$
\mathrm{p}_{X}(\mathrm{t})=\mathrm{i}_{\text {oX }}^{2}(\mathrm{t}) \mathrm{nr}_{\mathrm{LED}}+\mathrm{i}_{\mathrm{oX}}(\mathrm{t}) \mathrm{nV}_{\gamma_{-L E D}}
$$

where $\mathrm{X}$ represents the phase under study, $\mathrm{R}, \mathrm{S}$ or $\mathrm{T}$ which are given a fixed value to unify and simplify the analysis. Consequently, $\mathrm{X}$ is equal to 0 for phase $\mathrm{R}, 1$ for phase $\mathrm{S}$ and 2 for phase T. That being said, solving $\mathrm{i}_{\mathrm{OX}}$ in (2), renders,

$$
i_{o X}(t)=\frac{-n V_{\gamma_{-L E D}}+\sqrt{n^{2} V_{\gamma_{-L E D}^{2}}^{2}+4 n r_{\text {LED }} p_{X}(t)}}{2 n r_{\text {LED }}},
$$

where,

$$
p_{X}(t)=I_{g} V_{g} \sin ^{2}\left(\omega t-X \frac{2 \pi}{3}\right)
$$

$V_{g}$ and $I_{g}$ are the mains peak input voltage and current, respectively, and $\omega$ is the mains angular frequency.

By operating with (1) and (3), the output luminance can be obtained. However, this is not a practical expression and conclusions cannot be easily drawn from it, unless it is processed by a numerical computing environment. For that matter and considering that this is a periodic waveform, the Fourier series can be applied marking the $60^{\text {th }}$ harmonic as the limit in accordance to the flicker regulation, obtaining,

$$
\mathrm{L}_{\mathrm{o}}(\mathrm{t})=\frac{\mathrm{L}_{\max }+\mathrm{L}_{\min }}{2}-\frac{\mathrm{L}_{\max }-\mathrm{L}_{\min }}{2} \cos (6 \omega \mathrm{t}),
$$

where,

$$
\mathrm{L}_{\min }=\alpha \frac{-n V_{\gamma_{-\mathrm{LED}}}+\sqrt{\mathrm{n}^{2} \mathrm{~V}_{\gamma_{-\mathrm{LED}}}^{2}+3 \mathrm{nr}_{\mathrm{LED}} \mathrm{P}_{\mathrm{g}}}}{n r_{\mathrm{LED}}},
$$

and

$$
\begin{aligned}
& \mathrm{L}_{\max }=\alpha \frac{-n V_{\gamma_{-L E D}}+\sqrt{n^{2} V_{\gamma_{-L E D}^{2}}+4 n_{\text {LED }} P_{g}}}{2 n r_{\text {LED }}} \\
& +\alpha \frac{-n V_{\gamma_{-L E D}}+\sqrt{n^{2} V_{\gamma_{-L E D}^{2}}^{2}+\mathrm{nr}_{\text {LED }} P_{g}}}{n r_{\text {LED }}},
\end{aligned}
$$

are the maximum and minimum luminance of the LED luminaire, obtained from combining (1) and (3) and solving at $\omega \mathrm{t}=0$ and $\omega \mathrm{t}=\pi / 2$, respectively, and $\mathrm{P}_{\mathrm{g}}$ is the peak input power (i.e. $P_{g}=V_{g} I_{g}$ ) of one of the phases, considering that ideally all the phases demand the same amount of power.

In (5), it can be seen that the output luminance is comprised of a dc and a sinusoidal component of six times the line frequency. If $\mathrm{r}_{\text {LED }}$ is considered to be negligible, then (6) and (7) can be approximated by,

$$
\mathrm{L}_{\text {min }}\left(\mathrm{r}_{\mathrm{LED}}=0\right)=\mathrm{L}_{\max }\left(\mathrm{r}_{\mathrm{LED}}=0\right)=\frac{3 \alpha \mathrm{P}_{\mathrm{g}}}{2 n \mathrm{~V}_{\gamma_{-L E D}}} .
$$

Besides, the deviation between $\mathrm{L}_{\min }$ and $\mathrm{L}_{\max }$ becomes remarkable for the higher values of $r_{L E D}($ i.e. $>100 \Omega$ ), which are not achievable by the newer LEDs in the market. Hence, $L_{0}$ can be approximated to be a constant value close to either $\mathrm{L}_{\max }$ or $\mathrm{L}_{\text {min }}$, not showing any flicker on the light output in ideal conditions.

This analysis is able to validate the removal of the output capacitor. However, even if this operation is desirable in terms of light output, it is not from the perspective of the current supplied to each LED string due to the high current ripple withstood, which will require the LEDs to be oversized or duplicated to handle it. Therefore, a study needs to be carried out to evaluate the adequate size of the output capacitor in terms of the output current ripple in order to adequate the current levels while still using a film or ceramic capacitor with an acceptable lifespan.

\section{B. With output capacitor}

The addition of an output capacitor requires to start over the mathematical analysis previously carried out. For that reason, (2) can be rewritten as,

$$
p_{X}(t)=C_{X} v_{o X}(t) \frac{d v_{o X}(t)}{d t}+v_{o X}(t) i_{o X}(t),
$$

where $v_{0} x(t)$ can be defined as,

$$
\mathrm{v}_{\mathrm{oX}}(\mathrm{t})=\mathrm{n} \mathrm{V}_{\gamma_{-L E D}}+\mathrm{i}_{\mathrm{oX}}(\mathrm{t}) \mathrm{nr}_{\text {LED }}
$$


where $C_{X}$ defines the capacitance of the output capacitor of one of the cells that comprise the LED driver, as seen in Fig. 2. Equation (9) is a complex differential equation that requires to know beforehand the mathematical expression of the solution. Fortunately, it is known that the output current should follow the expression of a sinusoidalwaveform at twice the line frequency with a certain dc level. Hence,

$$
i_{o X}(t)=I_{a c} \sin \left(2 \omega t-\varphi-\frac{2 \pi}{3} X\right)+I_{d c},
$$

where $\mathrm{I}_{\mathrm{ac}}$ is the peak value of the ac component, $\mathrm{I}_{\mathrm{dc}}$ is the dc level of the output current and $\varphi$ represents a phase delay. Substituting (11) into (9), is the start point of this mathematical analysis in order to attain the three aforementioned parameters (i.e. $\mathrm{I}_{\mathrm{ac}}, \mathrm{I}_{\mathrm{dc}}$ and $\varphi$ ). The study for phase $\mathrm{R}$ yields,

$$
\begin{gathered}
\mathrm{P}_{\mathrm{g}} \sin ^{2}(\omega \mathrm{t})=A_{1} \mathrm{I}_{\mathrm{ac}} \cos (2 \omega \mathrm{t}-\varphi)+A_{2} \mathrm{I}_{\mathrm{ac}} \sin (2 \omega \mathrm{t}-\varphi) \\
+\left(\frac{\mathrm{I}_{\mathrm{ac}}^{2}}{2}+\mathrm{I}_{\mathrm{dc}}^{2}\right) \mathrm{nr}_{\mathrm{LED}}+\mathrm{I}_{\mathrm{dc}} \mathrm{nV}_{\gamma_{-\mathrm{LED}}},
\end{gathered}
$$

if the four times the line frequency components are removed and losses are not considered, where $\mathrm{A}_{1}$ and $\mathrm{A}_{2}$ are defined as,

$$
\begin{aligned}
& \mathrm{A}_{1}=\mathrm{C}_{\mathrm{X}} \mathrm{nr}_{\mathrm{LED}}\left(\mathrm{nr}_{\mathrm{LED}} \mathrm{I}_{\mathrm{dc}}+n \mathrm{~V}_{\gamma_{-\mathrm{LED}}}\right) 2 \omega \text {, } \\
& A_{2}=\left(2 \mathrm{nr}_{\mathrm{LED}} \mathrm{I}_{\mathrm{dc}}+\mathrm{nV} \gamma_{\gamma_{-\mathrm{LED}}}\right) .
\end{aligned}
$$

Grouping components in (12) in terms of the dc and sinusoidal components of double the line frequency renders,

$$
\frac{\mathrm{P}_{\mathrm{g}}}{2}=\left(\frac{\mathrm{I}_{\mathrm{ac}}^{2}}{2}+\mathrm{I}_{\mathrm{dc}}^{2}\right) \mathrm{nr}_{\mathrm{LED}}+\mathrm{I}_{\mathrm{dc}} n \mathrm{~V}_{\gamma_{-\mathrm{LED}}},
$$

and

$$
\frac{-P_{g}}{2} \cos (2 \omega t)=A_{1} I_{a c} \cos (2 \omega t-\varphi)+A_{2} I_{a c} \sin (2 \omega t-\varphi) .
$$

Looking at (15) and (16), it can be seen that both equations are dependent of $I_{a c}$ and $I_{d c}$ which gives a system of two equations and three unknown variables. In order to attain a useful model from an engineering perspective, there is one simplification that can be performed, which is removing $\mathrm{I}_{\mathrm{ac}}$ from (15). This is a fine approximation that dramatically decreases the complexity of the solutions. It can be performed considering that the maximum achievable value of $I_{a c}$ is equal to $I_{d c}$ obtained without an output capacitor. In fact, this approximation can only be performed for an LED string, having an error of less than $5 \%$, due to the lower impact of the current on the output voltage. Hence, $I_{d c}$ can be easily obtained by solving a second degree equation as,

$$
I_{d c}=\frac{-n V_{\gamma_{-L E D}}+\sqrt{n^{2} V_{\gamma_{-L E D}^{2}}^{2}+2 n r_{L E D} P_{g}}}{2 n r_{L E D}} .
$$

In order to attain $\mathrm{I}_{\mathrm{ac}}$ and $\varphi$, it is necessary to solve (16). This equation can be simply solved by applying wave superposition theory, which is widely used in other fields of study [23], reducing the problem to the sum of two plane waves with different amplitude. Hence,

$$
\begin{gathered}
\mathrm{I}_{\mathrm{ac}}=\frac{-P_{g}}{2 \sqrt{A_{1}^{2}+A_{2}^{2}}}, \\
\varphi=\tan ^{-1}\left(\frac{-A_{2}}{A_{1}}\right) .
\end{gathered}
$$

Having calculated all the parameters, a relationship between the required output capacitance for a certain peak-to-peak current ripple $(\Delta \mathrm{I})$ can be made from (18), as,

$$
\mathrm{C}_{\mathrm{X}}=\frac{1}{\mathrm{nr}_{\mathrm{LED}}\left(\mathrm{nr}_{\mathrm{LED}} \mathrm{I}_{\mathrm{dc}}+n \mathrm{~V}_{\gamma_{-\mathrm{LED}}}\right) 2 \omega} \sqrt{\frac{\mathrm{P}_{\mathrm{g}}^{2}}{4 \mathrm{I}_{\mathrm{dc}}^{2} \Delta \mathrm{I}^{2}}-\mathrm{A}_{2}^{2}} .
$$

At this point it is possible to study the impact of varying the output capacitor value on the output current by solving (17), (18) and (19) into (9). Fig. 4, shows this variation for the real data used in the experimental results section at maximum power, as can be seen, if an output capacitor of $1 \mu \mathrm{F}$ able to filter the switching frequency ripple is used, there is almost no impact in terms of the amplitude of the mains frequency compared to the scenario without output capacitor. The filtering of this lower frequency starts to be significant from $10 \mu \mathrm{F}$ onwards. In summary, this analysis show that it is possible to diminish the ripple enough without using an electrolytic capacitor, likewise, it is necessary to foresee under this conditions whether it is possible or not to obtain a constant de light output.

Substituting (11) into (1), gives the light output waveform of the proposed converter with an output capacitor in each cell, as

$$
\mathrm{L}_{\mathrm{o}}(\mathrm{t})=3 \alpha \mathrm{I}_{\mathrm{dc}}
$$

taking into account that the sinusoidal components cancel each other. Hence, it is feasible to attain a constant light output with a non-electrolytic capacitor that is also able to reduce the current ripple to acceptable levels.

\section{EXPERIMENTAL RESULTS}

For the sake of validating the proposal of this work to drive LEDs in three-phase power grids, a prototype has been built controlling three boost converters working in CCM with an MBC. The control of each cell is performed with the help of an analog IC, particularly the UCC3817 widely used for PFC. The

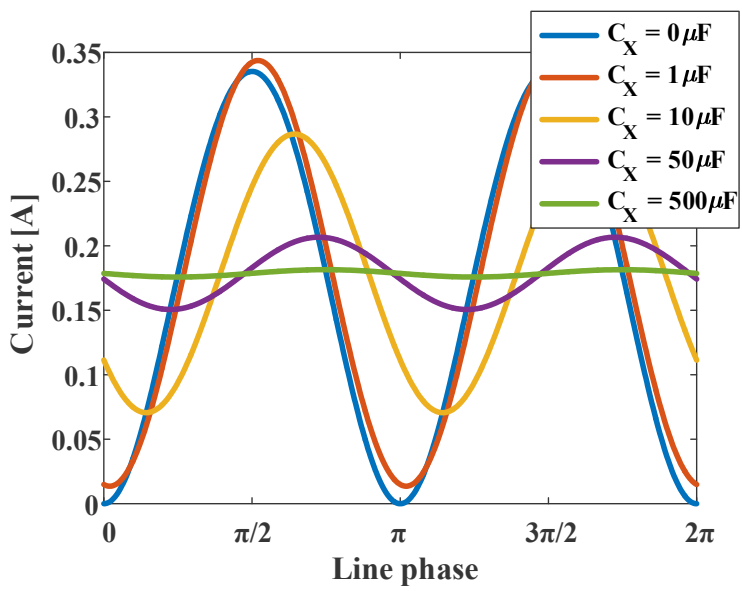

Fig. 4. Out put current versus line phase in terms of the output capacitor. 
LED driver is designed in such a way that each cell is required to drive two strings in parallel of 20 LEDs (L1505770502400000 ), which are equivalent to $490 \mathrm{~V}$ at $100 \mathrm{~W}$. The number of LEDs selected in series on a string is not done randomly and is picked ensuring that the sum of knee voltages from the LEDs in a string at the operating temperature is higher than the maximum input voltage in the worst case scenario of the power grid, which is around $400 \mathrm{~V}$ for the European power grid. This fact is based on the inherent behaviour of a boost converter which is only able to increase the voltage at its input. Otherwise, the driver would not be able to guarantee full dimming operation.

The components that comprise each of the cells are summarized in Table I.

Fig. 5, shows a picture of the designed prototype with its three cells, its central control unit and the designed luminaire. The central control unit is in charge of two functions, the first one being the start-up of the LED driver, and the second, giving the command to each cell to provide the LEDs with the same average current. In terms of the start-up, it can be tackled in a similar fashion to [24], [25]. Following the same principle, the cells are off at the start of the LED driver until the output capacitors are all charged to the maximu $m$ voltage achievable in a star connection through the inrush current diode, at which point all the cells are started up. Hence, an isolated signal is given to the controlunit of each cell to start-up the boost converter. In the picture, it can also be seen that the LED strings are distributed between phases in order to ensure a better blend of the light.

\section{A. Outputcapacitoranalysis}

The first experimental analysis is carried out in order to validate the operation of one of the cells when it is connected to

\section{TABLE I. SUMMARIZED CELL COMPONENTS}

\begin{tabular}{cl}
\hline \hline Fig. 2 reference & VALUE \\
\hline $\mathrm{L}_{1}, \mathrm{~L}_{2}$ and $\mathrm{L}_{3}$ & $1.7 \mathrm{mH}$ \\
$\mathrm{Q}_{1}, \mathrm{Q}_{2}$ and $\mathrm{Q}_{3}$ & IPW65R190C7 \\
$\mathrm{D}_{1}, \mathrm{D}_{2}$ and $\mathrm{D}_{3}$ & IDH06SG60C \\
$\mathrm{C}_{\mathrm{R}}, \mathrm{C}_{\mathrm{S}}$ and $\mathrm{C}_{\mathrm{T}}$ & $10 \mu \mathrm{H}$ \\
\hline \hline
\end{tabular}

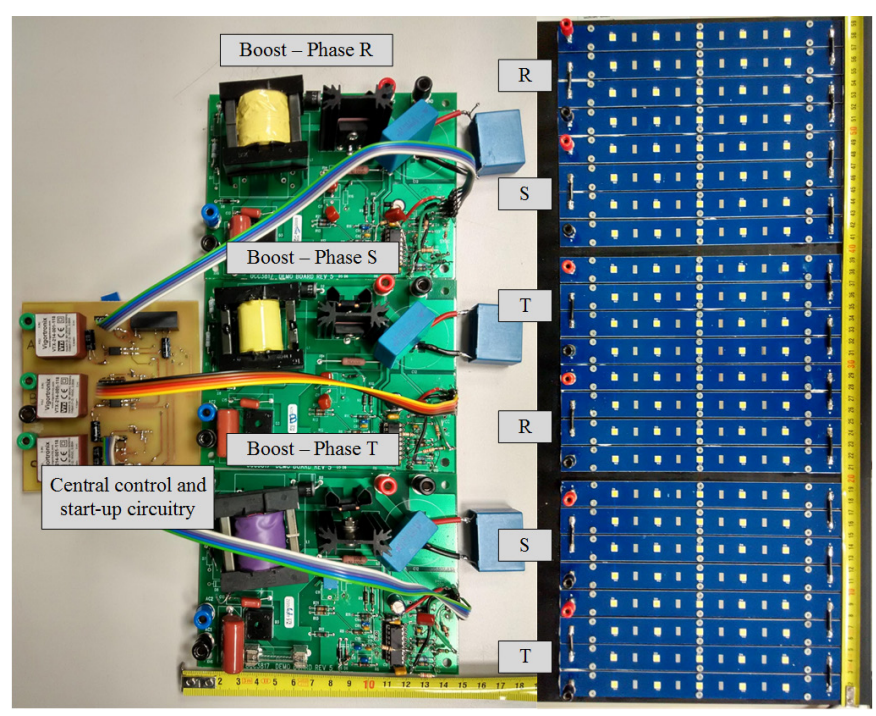

Fig. 5. Photograph of the experimental setup. a single-phase power grid at its input and an LED string at its output with a high current ripple and voltage.

In that sense, Fig. 6 shows that the inputcurrent is adequately in phase with the input voltage ensuring, as expected, an LFR performance at the maximum output power of the cell (i.e. $100 \mathrm{~W}$ ) while working in CCM. Particularly, Fig. 6 (a) depicts the high current ripple due to the use of a $10 \mu \mathrm{F}$ and the light output measured with a transimpedance amplifier (TSL-257), located at a fixed distance of $20 \mathrm{~cm}$, which supplies at its output a certain voltage, $\mathrm{VL}$, depending on the light falling upon the photodiode. In contrast, Fig. 6 (b) shows the voltage withstood by the LEDs for this scenario in which the lowest voltage never falls below the $400 \mathrm{~V}$ mark set before. However, this is the best case scenario, as the lowest current is far from being zero to test whether the selection of LEDs is acceptable. In order to ensure an adequate performance in terms of its output voltage, Fig. 7, shows a snapshot of the oscilloscope when dimming the driver to an output power of $25 \mathrm{~W}$, in which it can be seen that the output current reaches zero, and it is at this point where the minimum output voltage is reached being slightly higher than $400 \mathrm{~V}$.

Although, the operation for an LED load has been validated, the analys is carried out in terms of the output capacitor has not. For that matter, Fig. 8 summarizes three different measurements of current across the LEDs performed at maximum output power

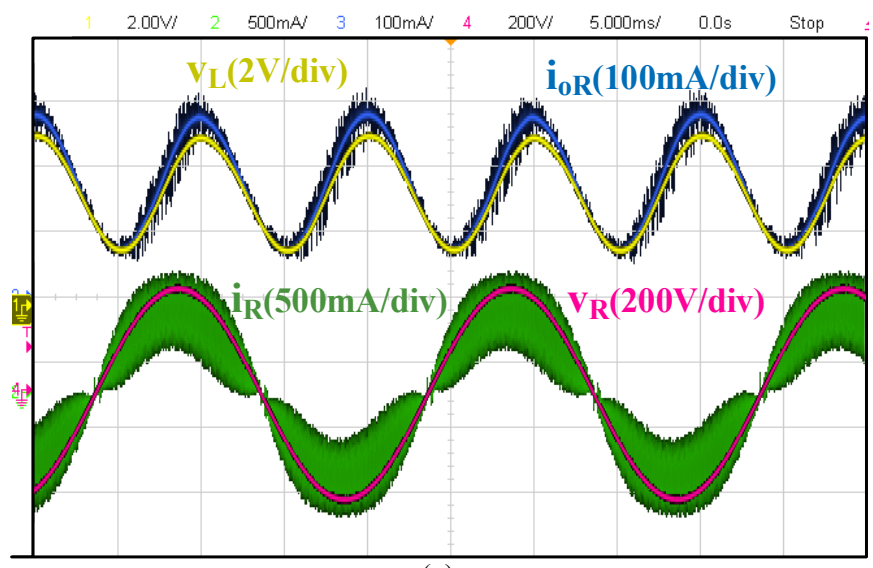

(a)

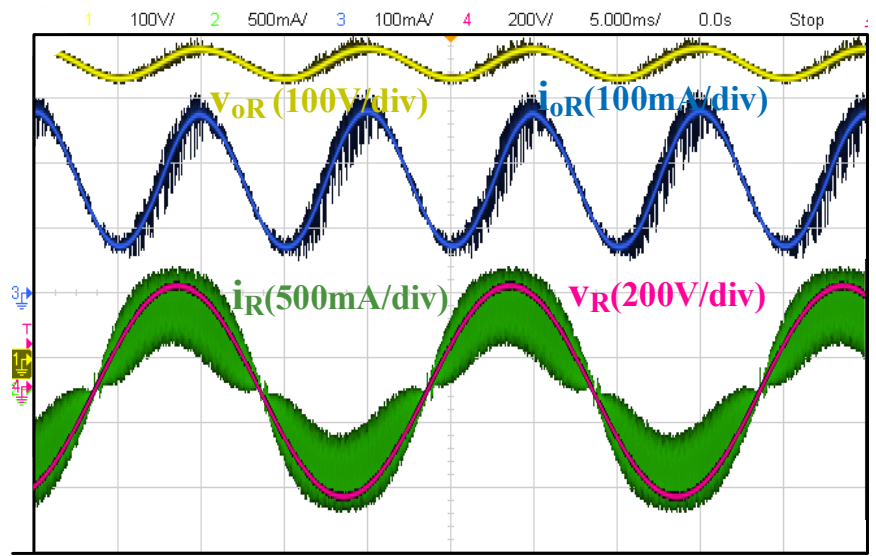

(b)

Fig. 6. Standalone operation of one the cells that comprise the LED driver at maximum power, depicting both input and output current, input voltage, and (a) light output measurement or(b) out put voltage measurement. 
after being extracted from the oscilloscope, considering the only variable that changes in the cell is the value of the output capacitor. As expected, the higher the value of the capacitance, the lower the current ripple. In fact, if these measurements are compared with the ones from the prior mathematical analysis, depicted in Fig. 4, for their respective capacitance value, it can be seen that the developed model is extremely accurate. Please note, that the difference between phases in Fig. 4 and Fig. 8 can be explained due to the phase shift introduced by the trigger, see Fig. 6.

\section{B. Evaluation in a real three-phase power grid}

After having validated the operation of the cells individually, the driver has been as sembled and connected to the real three-phase power grid by means of a three wire connection. Under these conditions the waveforms presented in Fig. 9 have been obtained from the oscilloscope at maximum load, i.e. 300 W. Fig. 9 (a) depicts the input waveforms of the three-phase LED driver, where it can be seen that for phase R the LFR performance is achieved. Consequently, it can be assumed for the other two phases, considering the phase-shift between the currents. Moreover, Fig. 9 (b) shows the current across the LED strings for each of the cells presenting extremely similar current levels. Its sum, measured again with a transimpedance amplifier

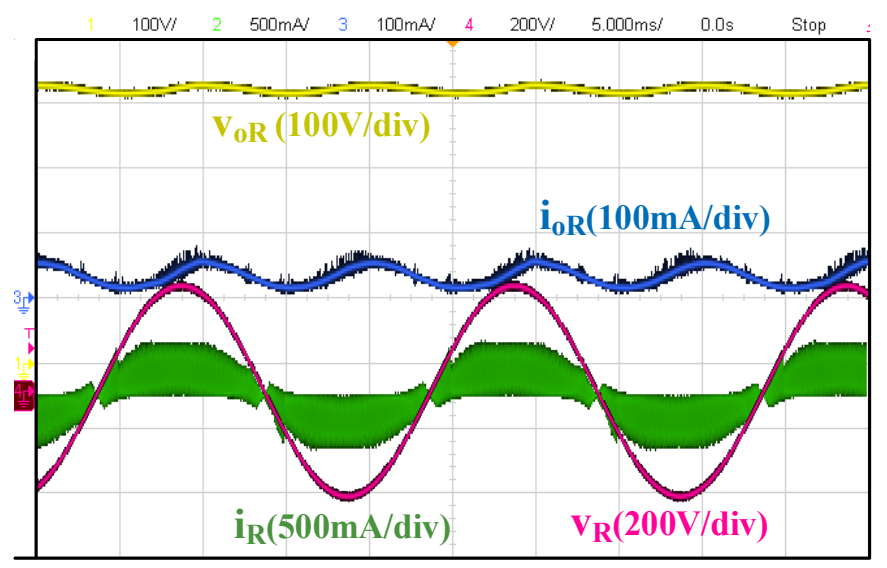

Fig. 7. Standalone operation of one the cells that comprise the LED driver at a quarter of the maximum output power.

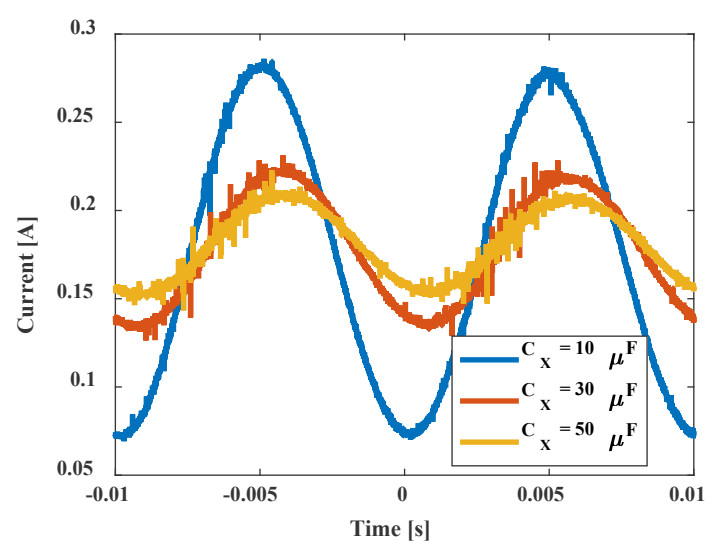

Fig. 8. Output current across the LEDs when varying the output capacitor of the cell.

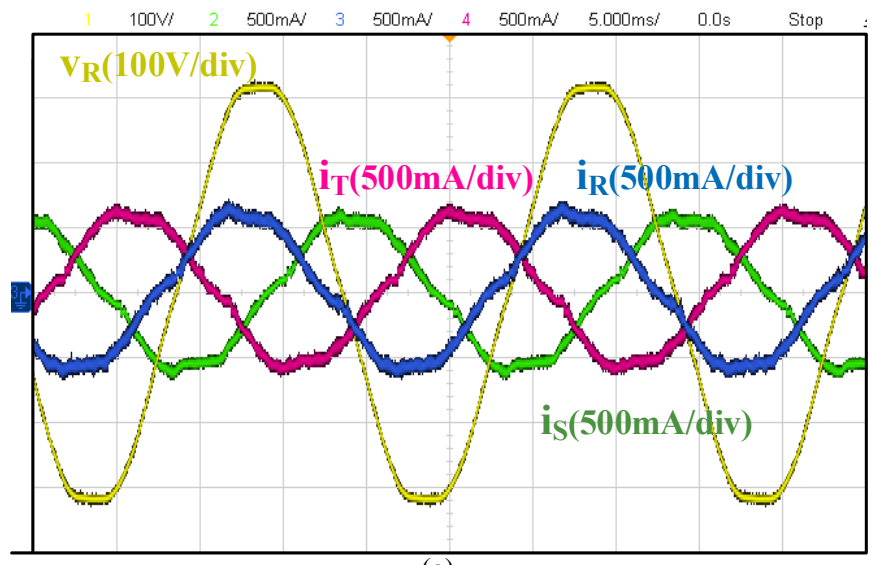

(a)

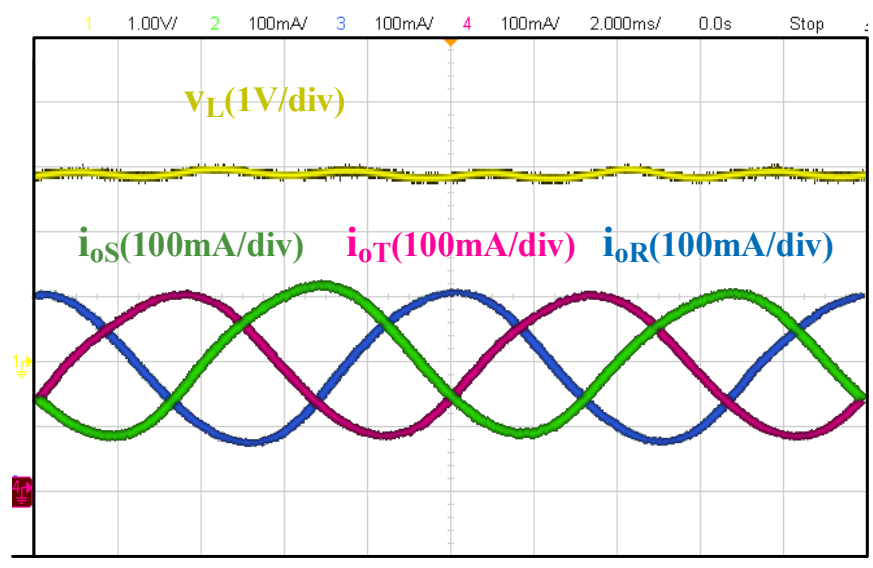

(b)

Fig. 9. Experimental waveforms at maximum load. (a) Input voltage and currents. (b) Output currents and light output.

in this case at a fixed distance of $60 \mathrm{~cm}$, is comprised of a dc level with a low frequency ripple at $300 \mathrm{~Hz}$. Considering the amplitude of this ripple the light output of the driver can be considered to be constant.

The almost constant light output of the driver validates the analysis carried out. However, the low frequency ripple needs to be evaluated to ensure a flicker free performance. In that respect, the IEEE standard 1789-2015 will be used to limit the biological effects and detection of flicker in general illumination. In order to achieve this performance the modulation (\%), normally referred as Mod.(\%), should be kept withing the shaded region defined in [26] for all the harmonic components of the light output. Consequently, the Mod. (\%) for each of the harmonics can be defined as follows,

$$
\operatorname{Mod} .(\%)(m)=\frac{\mathrm{L}_{\mathrm{H}, \text { max }}(\mathrm{m})-\mathrm{L}_{\mathrm{H}, \text { min }}(\mathrm{m})}{\mathrm{L}_{\mathrm{H}, \text { max }}(\mathrm{m})+\mathrm{L}_{\mathrm{H}, \text { min }}(\mathrm{m})+\mathrm{L}_{\mathrm{dc}}} \cdot 100,
$$

where $\mathrm{m}$ defines the number of the harmonic in reference to the fundamental one, $\mathrm{L}_{\mathrm{dc}}$ represents the average luminance of the LED driver, and $\mathrm{L}_{\mathrm{H}, \max }$ and $\mathrm{L}_{\mathrm{H} \text {,min }}$ correspond to the maximum and minimum luminance for harmonic $\mathrm{m}$, respectively.

The luminance over time of the LED driver has been obtained for a line period and has been processed with MATLAB in order to attain the harmonic components with the help of the Fourier series, considering the line frequency as the 
fundamental frequency. Fig. 10 shows that the Mod. (\%) of all the harmonic components $50 \mathrm{~Hz}$ to $3 \mathrm{kHz}$ fall under the shaded region which represents the recommended operating area from. A flicker free performance of the proposed LED driver can then be assured from this analysis.

\section{Electrical performance}

The proposal of summing the light output of each cell has been validated for the proposed LED driver. However, there are two characteristics that need to be evaluated before closing the analysis. The first one is the compliance with the regulation IEC 61000-3-2, in which the input current harmonics at maximum power are compared with the limits set in the aforementioned regulation for each of the phases. Fig. 14 summarizes the results from this comparison assuring compliance with the regulation.

In that sense, there are a few parameters that can be of interest from the point of view of the input current quality, as are the THD and PF. These parameters are summarized in Table II for three different input voltages with their respective efficiency at full load. As can be seen, the measured THD is about $7 \%$ and the $\mathrm{PF}$ is 0.99 , furthermore, the LED driver presents an efficiency of $96.9 \%$ for the lowest input voltage and $98.2 \%$ for its maximum.

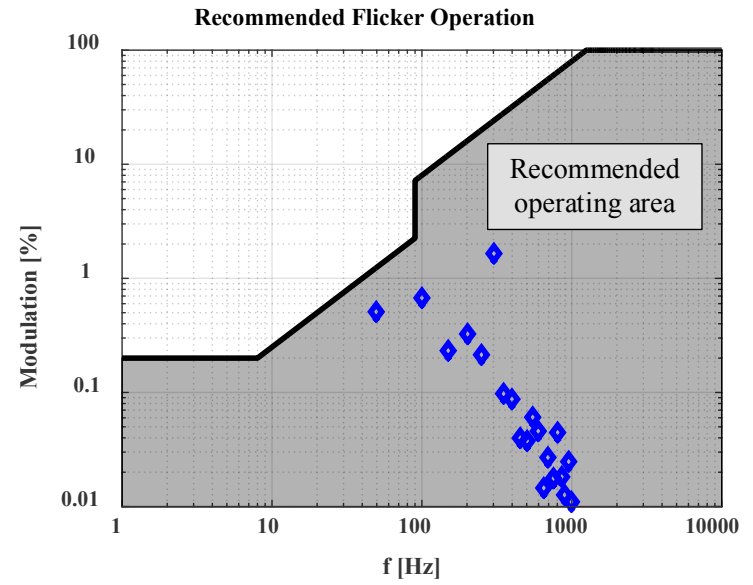

Fig. 10. Recommended flicker operation for the proposed LED driver [26].

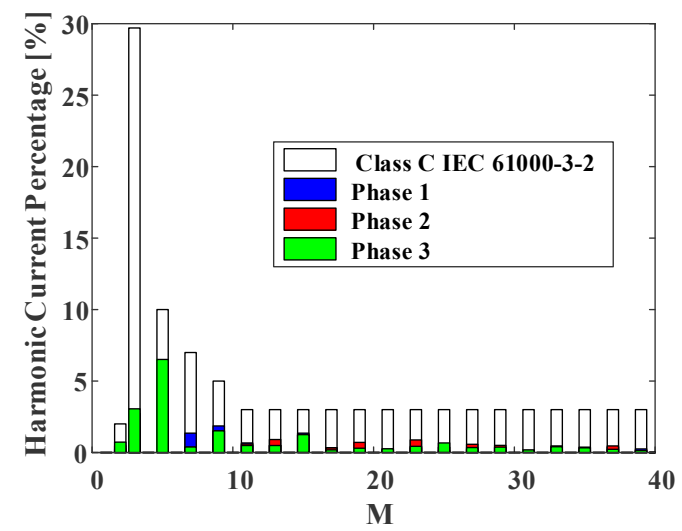

Fig. 11. Harmonic content of each phase for the proposed driver under study assuring compliance with Class C IEC 61000-3-2.
TABLE II. SUMMARY OF THD, PF AND EFFICIENCY FOR DIFFERENT INPUT VOLTAGES

\begin{tabular}{llccc}
\hline \hline $\begin{array}{c}\text { Phase/ Max. } \\
\text { input voltage }\end{array}$ & THD [\%] & R & S & T \\
\hline \multirow{3}{*}{380 Vrms } & PF & 0.997 & 0.997 & 0.997 \\
& Efficiency [\%] & & 96.9 & \\
& THD [\%] & 6.7 & 7.1 & 7.3 \\
400 Vrms & PF & 0.995 & 0.995 & 0.995 \\
& Efficiency [\%] & & 97.5 & \\
& THD [\%] & 7.4 & 7.6 & 7.9 \\
420 Vrms & PF & 0.992 & 0.992 & 0.997 \\
& Efficiency [\%] & & 98.2 & \\
\hline \hline
\end{tabular}

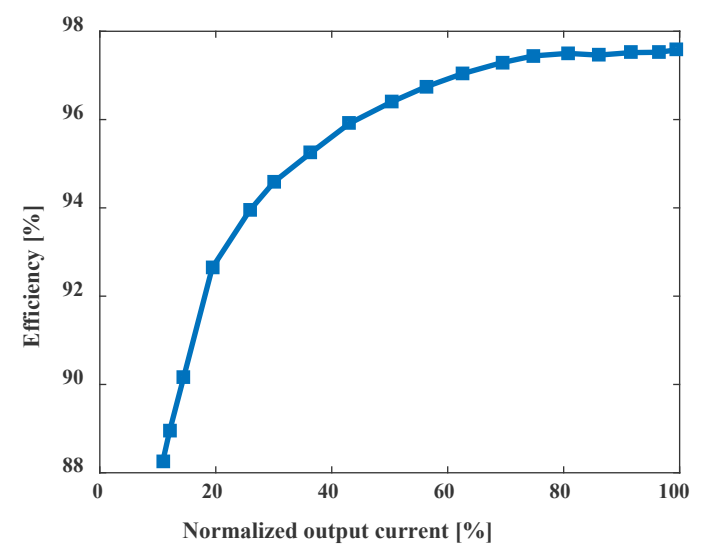

Fig. 12.Electrical efficiency measured under different dimming conditions at $400 \mathrm{Vrms}$.

Finally, the efficiency has been measured under different dimming conditions at $400 \mathrm{Vrms}$, as shown in Fig. 15, obtaining a maximum efficiency of $97.5 \%$ at full load, which is equivalent to $42.000 \mathrm{~lm}$, outputting a luminous efficacy of $140 \mathrm{~lm} / \mathrm{W}$.

\section{CONCLUSIONS}

The presented three-phase ac-dc LED driver is aimed for high power luminaires that require a long lifespan, generally in inaccessible places. Hence, the removal of the electrolytic capacitor becomes critical in this very application. This fact is possible in balanced three-phase ac-dc converters due to the non-pulsating behaviour of the power grid. However, high power luminaires would require a modular two stage three-phase solution which increases the cost and reduces the reliability. Furthermore, the compliance with the most restrictive harmonic regulation reduces the possible converters that could be used for this task. The proposal of this paper dis poses of both the second stage and the electrolytic capacitor, reducing cost and increasing both lifespan and reliability of the LED driver, by taking advantage of the properties of the light in order to sum the light output of each phase. In contrast, galvanic is olation is sacrificed in this solution in pursuit of higher efficiencies, since it is no longer required to connect the output of the cells.

In order to remove the electrolytic capacitor from the boost PFC that comprises each cell, a study is carried out to diminish the its size by considering the feasibility of driving LEDs with high current ripples while achieving a constant light output. 
In summary, the experimental results have shown an LED driver capable of achieving a constant light output that meets the flicker regulation, compliance with the harmonic injection regulation and a high efficiency. In fact, the efficiency increase compared to three-phase state of the art LED drivers is not inconsequential, improving those solutions by more than $6 \%$ efficiency [7], [9], [11], [16]. Furthermore, the control of the LED driver is not more complex or costly, becoming a possibility the input parallelization of cells per phase, to further increase the power capabilities of the driver, without increasing or changing the central unit. These reasons make this driver an ambitious solution to drive LEDs in three-phase power grid when galvanic isolation is not required.

\section{REFERENCES}

[1] M. Arias, A. Vazquez, and J. Sebastian, "An overview of the AC-DC and DC-DC converters for LED lighting applications," Automatika-J. Control, Measure., Electr., Comput. Commun., vol. 53, pp. 156-172, 2012.

[2] ENERGY STAR ${ }^{\circledR}$ Program Requirements Product Specification for Lamps (Light Bulbs) - Elegibility Criteria, V. 2.0, Oct. 2016.

[3] ENERGY STAR® Program Requirements Product Specification for Luminaires (Light Fixtures) - Elegibility Criteria, V. 2.0, Jan. 2016.

[4] Electromagnetic compatibility (EMC) - Part 3-2: Limits - Limits for harmonic current emissions (equipment input current $<16$ A per phase), document IEC 61000-3-2, 2014.

[5] J. W. Kolar, H. Ertl and F. C. Zach, "A novel three-phase single-switch discontinuous-mode AC-DC buck-boost converter with high-quality input current waveforms and isolated output," in IEEE Transactions on Power Electronics, vol. 9, no. 2, pp. 160-172, Mar 1994.

[6] J. Minbock and J. W. Kolar, "Design and experimental investigation of a single-switch three-phase flyback-derived power factor corrector," INTELEC. Twenty-Second International Telecommunications Energy Conference (Cat. No.00CH37131), Phoenix, AZ, 2000,pp. 471-478.

[7] M. R. Mendonça, E. Mineiro; Sá, R. P. Coutinho and F. L. M. Antunes, "AC-DC single-switch three-phase converter with peak current control for power LEDs," Industry Applications (INDUSCON), 2014 11th IEEE/IAS International Conference on, Juiz de Fora, 2014, pp. 1-6.

[8] R. F. Brewster and A. H. Barret, "Three Phase AC to DC voltage converter with Power Line Harmonic Current Reduction", U.S. patent 4 143 414, March 6, 1979.

[9] I. Castro, D. G. Lamar, M. Arias; M. M. Hernando, J. Sebastian, "Multicell three phase ac-dc driver for HB-LED lighting applications," in IEEE Transactions on Industry Applications, vol.PP, no.99, pp.1-1.

[10] J. Sebastián, I. Castro, D. G. Lamar, A. Vázquez and K. Martín, "High power factor modular polyphase AC/DC converters with galvanic isolation based on Resistor Emulators," 2016 IEEE Applied Power Electronics Conference and Exposition (APEC), Long Beach, CA, 2016, pp. 25-32.
[11] I. Castro, D. G. Lamar, M. Arias, J. Sebastian and M. M. Hernando, "Three phase converter with galvanic isolation based on loss-free resistors for HB-LED lighting applications," 2016 IEEE Applied Power Electronics Conference and Exposition (APEC), Long Beach, CA, 2016.

[12] M. Arias, D. G. Lamar, J. Sebastian, D. Balocco and A. A. Diallo, "HighEfficiency LED Driver Without Electrolytic Capacitor for Street Lighting," in IEEE Transactions on Industry Applications, vol. 49, no. 1, pp. 127-137, Jan.-Feb. 2013.

[13] X. Wu, J. Zhang and Z. Qian, "A Simple Two-Channel LED Driver With Automatic Precise Current Sharing," in IEEE Transactions on Industrial Electronics, vol. 58, no. 10, pp. 4783-4788, Oct. 2011.

[14] M. Arias, M. Fernández Diaz, D. G. Lamar, D. Balocco, A. Aguissa Diallo and J. Sebastián, "High-Efficiency Asymmetrical Half-Bridge Converter Without Electrolytic Capacit or for Low-Output-Voltage AC-DC LED Drivers," in IEEE Transactions on Power Electronics, vol. 28, no. 5, pp. 2539-2550, May 2013.

[15] M. Arias, I. Castro, D. G. Lamar, A. Vázquez and J. Sebastián, "Optimized design of a high input-voltage-ripple-rejection converter for LED lighting," in IEEE Transactions on Power Electronics, vol. PP, no. 99, pp. 1-1.

[16] R. P. Coutinho, K. C. A. de Souza, F. L. M. Antunes and E. Mineiro Ś, "Three-Phase Resonant Switched Capacitor LED Driver With Low Flicker," in IEEE Transactions on Industrial Electronics, vol. 64, no. 7, pp. 5828-5837, July 2017.

[17] C. S. Wong, K. H. Loo, Y. M. Lai, M. H. L. Chow and C. K. Tse, "An Alternative Approach to LED Driver Design Based on High-Voltage Driving," in IEEE Transactions on Power Electronics, vol. 31, no. 3, pp. 2465-2475, March 2016.

[18] N. Pousset, B. Rougie, and A. Razet, "Impact of current supply on LED colour," Lighting Res. Technol., vol. 42, no.4, pp.371-383, August 2010.

[19] W. Feng, Y. He and F. G. Shi, "Investigation of LED Light Output Performance Characteristics Under Different Alternating Current Regulation Modes," in IEEE Journal of Selected Topics in Quantum Electronics, vol. 17, no. 3, pp. 720-723, May-June 2011.

[20] H. Sun, "Sports Lighting - Design Considerations For TheBeijing 2008 Olympic Games", GE Beijing 2008 Olympic Games Solutions, 2008.

[21] L. H. Dixon, "High power factor preregulators for off-line power supplies", Unitrode Power Supply Design Seminar, 1988, pp. 6.1-6.16.

[22] L. Rossetto, G. Spiazzi, and P. Tenti, "Control techniques for power factor correction converters, " in Proc. Int. Conf. Power Electron. Motion Control, Warsaw, Poland, 1994,pp. 1310-1318.

[23] T. Freegarde. Introduction to the Physics of Waves. Cambridge University Press, 2012.

[24] L. Huber, M. Kumar and M. M. Jovanovic, "Analysis, design, and evaluation of three-phase three-wire isolated ac-dc converter implemented with three single-phase converter modules," 2016 IEEE Applied Power Electronics Conference and Exposition (APEC), Long Beach, CA, 2016,pp.38-45.

[25] M. Kumar, L. Huber and M. M. Jovanovic, "Startup procedure for threephase three-wire isolated ac-dc converter implemented with three singlephase converter modules," 2016 IEEE Applied Power Electronics Conference and Exposition (APEC), Long Beach, CA, 2016, pp. 46-53.

[26] IEEE Recommended Practices for Modulating Current in HighBrightness LEDs for Mitigating Health Risks to Viewers," in IEEE Std 1789-2015, vol., no., pp.1-80, June 52015. 